OLIVEIRA NS; CARVALHO FILHO JLS; SILVA DO; PASTORIZA RJG; MELO RA; SILVA JW; MENEZES D. 2015. Seleção e parâmetros genéticos de progênies de coentro tolerantes ao calor. Horticultura Brasileira 33: 319-323. DOI: http://dx.doi.org/10.1590/S0102-053620150000300007

\title{
Seleção e parâmetros genéticos de progênies de coentro tolerantes ao calor
}

\author{
Natália S Oliveira ${ }^{1}$; José LS Carvalho Filho²; Drielle O Silva²; Rhuan JG Pastoriza ${ }^{2}$; Roberto A Melo²; \\ José W Silva²; Dimas Menezes ${ }^{2}$ \\ ${ }^{1}$ Universidade Federal de Lavras, UFLA-Depto. Agricultura, Lavras-MG, Brasil; natalia.agro@yahoo.com.br; ²Universidade Federal \\ Rural de Pernambuco, UFRPE-Depto. Agronomia, Recife-PE, Brasil; joseluiz.ufrpe@yahoo.com.br; drika_nap@hotmail.com; \\ rhuangp@hotmail.com; robertoagronomo@yahoo.com.br; jwsamaral@hotmail.com; dimas@depa.ufrpe.br
}

\begin{abstract}
RESUMO
O coentro é uma hortaliça bastante apreciada como condimento. Em Pernambuco, a cultivar Verdão é uma das mais plantadas, porém um dos problemas dessa cultivar tem sido o seu pendoamento precoce. Cultivares com maior período de crescimento vegetativo e tolerantes ao pendoamento precoce têm sido procuradas pelos produtores. Entretanto, são poucas as pesquisas realizadas no Brasil com cultivares de coentro com essas características. Uma alternativa seria identificar populações promissoras para obtenção de linhagens adaptadas ao calor dentro da cultivar Verdão, uma vez que essa cultivar apresenta ciclo curto e variabilidade genética para este caráter. O objetivo deste trabalho foi estimar parâmetros genéticos e predizer o valor genético de progênies de meio-irmãos de coentro pela metodologia dos modelos lineares mistos (procedimento REML/BLUP) quanto aos caracteres número de dias para início do pendoamento, altura de plantas, diâmetro do caule e massa fresca, além de estimar o número mínimo de progênies adequado para representar uma população de coentro derivada da cultivar Verdão. Oitenta e cinco progênies de meio-irmãos do segundo ciclo de seleção recorrente foram conduzidas em dois experimentos. Foram obtidas estimativas de herdabilidade altas e relações $\mathrm{CV}_{\mathrm{g}} / \mathrm{CV}_{\mathrm{e}}$ superiores à unidade para todos os caracteres avaliados, exceto para altura de plantas. A estimativa de parâmetros genéticos permitiu concluir que as progênies de coentro apresentam variabilidade genética para os caracteres número de dias para início do pendoamento, diâmetro do caule e massa fresca. O número mínimo de progênies adequado para estimar os parâmetros genéticos e representar a população de coentro é de 68 . Treze progênies de meio-irmãos podem ser selecionadas para dar continuidade ao programa de melhoramento de coentro para tolerância ao calor.
\end{abstract}

Palavras-chave: Coriandrum sativum, melhoramento vegetal, condimento.

\section{ABSTRACT \\ Selection and genetic parameters of coriander progenies with heat tolerance}

Coriander is a vegetable crop very appreciated as a condiment. The cultivar Verdão is one of the most cultivated in the state of Pernambuco (Brazil), however it is susceptible to premature bolting. Cultivars with longer vegetative growth and tolerant to early bolting have been sought by producers. Nevertheless, a few studies are conducted in Brazil on coriander cultivars with such characteristics. An alternative would be the identification of promising populations to obtain lineages adapted to heat within the cultivar Verdão, since this cultivar has a short cycle and genetic variability for this characteristic. The aim of this study was to estimate the genetic parameters and predict the genetic value of half-sib coriander progenies by the methodology of mixed linear models (REML/BLUP procedure) regarding the characters number of days to the beginning of bolting, plant height, stem diameter and fresh weight. Besides estimating the minimum number of suitable progenies to represent a coriander population derived from the cultivar Verdão. Eighty-five half-sib progenies of the second cycle of recurrent selection were conducted in two experiments. The estimation of high heritability and the $\mathrm{CV}_{\mathrm{g}} /$ $\mathrm{CV}_{\mathrm{e}}$ ratio above the unit for all traits were obtained, except for plant height. The estimation of genetic parameters showed that coriander progenies exhibit genetic variability for the characters number of days to the beginning of bolting, stem diameter and fresh weight. The minimum number of suitable progenies to estimate genetic parameters and to represent the coriander population is 68 progenies. Thirteen half-sib progenies may be selected to carry on the coriander breeding program regarding heat tolerance.

Keywords: Coriandrum sativum, crop breeding, heat tolerance, condiment.

(Recebido para publicação em 21 de novembro de 2014; aceito em 31 de março de 2015)

(Received on November 21, 2014; accepted on March 31, 2015)

$\mathrm{O}_{\mathrm{e}}^{\mathrm{c}}$ coentro (Coriandrum sativum) é uma hortaliça anual da família Apiaceae com origem no mediterrâneo. Suas folhas e sementes são apreciadas como condimento e o óleo essencial extraído de suas sementes é utilizado pela indústria farmacêutica, de perfumes e de cosméticos (Kumar et al., 2008).
Em 2009, foram comercializadas 508 toneladas de sementes de coentro das cultivares Verdão e Português podendo-se estimar que a área plantada no país 
com essas cultivares foi de 36.679 ha (ABCSEM, 2010).

Pode-se destacar os trabalhos de melhoramento genético da espécie como avaliação da variabilidade genética em progênies de meio-irmãos de coentro (Melo et al., 2009b), caracterização morfológica (Melo et al., 2009a) e avaliação de linhagens de coentro com pendoamento mais tardio (Maciel et al., 2012). Por mais que haja cultivares de boa aceitação comercial, não há cultivares recomendas para as diversas regiões produtoras (Oliveira et al., 2007) e para os diversos sistemas de produção.

A cultivar Verdão possui grande importância econômica em Pernambuco e é uma das cultivares mais plantadas no estado por ter ciclo curto e apresentar resistência a doenças de folhagens. Foi lançada no ano de 1988 pela empresa Hortivale. É rústica, bastante vigorosa, possui folhas com coloração verde escura e é colhida com 30 a 40 dias após o plantio (Hortivale, 2011). Porém, possui uma característica desfavorável para a produção de massa verde que é sua suscetibilidade ao pendoamento precoce.

O pendoamento é marcado pelo alongamento do caule e redução da produção de folhas para a emissão do pendão floral e ocorre durante a transição da fase vegetativa para reprodutiva. Esse processo é estimulado pelo aumento no comprimento do dia (Okut \& Yidirim, 2005) e por temperaturas elevadas. Com isso, as plantas mais precoces atingem o ponto de colheita com tamanho reduzido.

Os programas de melhoramento genético do coentro devem desenvolver cultivares com maior tolerância ao pendoamento precoce, uma vez que as plantas, ao iniciarem o pendoamento, deslocam reservas para o pendão floral resultando em folhas menores e com menor qualidade. Uma alternativa para contornar esse problema seria a seleção de plantas precoces e tolerantes ao calor dentro da cultivar Verdão, uma vez que essa cultivar é bastante conhecida pelos produtores e apresenta variabilidade genética para este caráter (Melo et al., 2009b), o que contribuiria para o aumento da produção de massa verde de coentro sem custos adicionais aos agricultores.
As estimativas de parâmetros genéticos são fundamentais no melhoramento de plantas, uma vez que permitem identificar a natureza de ação dos genes envolvidos no controle dos caracteres quantitativos e avaliar a eficiência de diferentes estratégias de melhoramento para obtenção de ganhos genéticos e manutenção de uma base genética adequada nas populações (Cruz \& Carneiro, 2006). Os procedimentos ótimos de estimação/predição REML/BLUP (máxima verossimilhança restrita/melhor predição linear não viciada) podem ser úteis nesse sentido.

$\mathrm{O}$ número mínimo de famílias de meio-irmãos é a quantidade adequada de progênies para representar uma população e que permite obter estimativas consistentes e estáveis dos parâmetros genéticos, uma vez que os indivíduos de uma progênie de meio-irmãos são geneticamente diferentes (Granate et al., 2001).

Diante disso, o objetivo deste trabalho foi estimar parâmetros genéticos e predizer o valor genético de progênies de meio-irmãos de coentro pela metodologia dos modelos lineares mistos quanto aos caracteres número de dias para início do pendoamento, altura de plantas, diâmetro do caule e massa fresca, além de estimar o número mínimo de progênies adequado para representar uma população de coentro derivada da cultivar Verdão.

\section{MATERIAL E MÉTODOS}

Os experimentos foram conduzidos na Horta da Universidade Federal Rural de Pernambuco em Recife-PE (8'54'47', S, 34 54 '47', O, altitude 6 $\mathrm{m})$. As progênies de meio-irmãos de coentro foram obtidas pelo programa de melhoramento da UFRPE. Foi feita a seleção antes do florescimento de plantas tolerantes ao pendoamento precoce dentro da cultivar Verdão. O método de melhoramento utilizado foi a seleção recorrente fenotípica.

As plantas de coentro da cultivar Verdão foram conduzidas em canteiros e foi feito o descarte das plantas que pendoaram primeiro, aumentando assim a frequência de alelos favoráveis ao pendoamento tardio. Foram colhidas as sementes dessas plantas que deram origem a sementes de plantas do ciclo $\mathrm{C} 1$. O processo foi repetido e foram obtidas as sementes das progênies de meio-irmãos do ciclo $\mathrm{C} 2$ tolerantes ao pendoamento precoce.

Devido à grande quantidade de progênies obtidas pelo programa, foi necessário fazer o plantio em dois experimentos. Os experimentos foram conduzidos em casa de vegetação coberta com filme de polietileno transparente de 150 micras e com tela nas laterais. A semeadura foi realizada em bandejas de poliestireno expandido de 200 células utilizando três sementes por célula. $\mathrm{O}$ desbaste foi realizado aos 10 dias, deixando-se apenas uma planta por célula. Aos 14 dias foi feito o transplante das mudas para vasos de 2,8 L contendo pó de coco. As parcelas foram compostas por sete plantas dispostas em cada vaso.

A semeadura das progênies do primeiro experimento foi realizada em janeiro e a colheita em março de 2012. As progênies do segundo experimento foram semeadas em março e a colheita foi feita em abril. Na época de condução dos experimentos, a temperatura média da cidade de Recife foi de $28^{\circ} \mathrm{C}$ (variando de 24 a $33^{\circ} \mathrm{C}$ ) e umidade relativa de 74\% (variando de 57 a 90\%).

As fertirrigações foram realizadas diariamente por gotejamento, de acordo com as necessidades da cultura, utilizando a solução nutritiva contendo nitrato de cálcio $1 \mathrm{~g} / \mathrm{L}$, nitrato de potássio 0,25 $\mathrm{g} / \mathrm{L}$, sulfato de potássio $0,2 \mathrm{~g} / \mathrm{L}$, cloreto de potássio $0,15 \mathrm{~g} / \mathrm{L}, \mathrm{MKP} 0,25 \mathrm{~g} / \mathrm{L}$, sulfato de magnésio $0,5 \mathrm{~g} / \mathrm{L}, 6,666 \times 10^{4}$ $\mu \mathrm{L} / \mathrm{L}$ de solução de ácido bórico (25 $\mathrm{g} / \mathrm{L}), 2,666 \times 10^{-2} \mathrm{~g} / \mathrm{L}$ de Quelatec, $6,6 \times 10^{2} \mu \mathrm{L} / \mathrm{L}$ de Chelal Zinco e 0,02666 $\mathrm{g} / \mathrm{L}$ de Ultra Ferro.

A colheita ocorreu quando mais de $50 \%$ das plantas da parcela havia iniciado o pendoamento. Foram avaliados os caracteres número de dias para início do pendoamento, diâmetro do caule, altura de plantas e massa fresca. $\mathrm{O}$ número de dias para início do pendoamento foi contado a partir da semeadura das progênies nas bandejas. O diâmetro do caule foi medido com o auxílio de paquímetro na base da planta; foram avaliadas duas plantas de cada parcela. A altura média 
das plantas da parcela foi medida com uma régua e a massa fresca das plantas foi obtida com balança de precisão, sendo avaliadas todas as plantas pendoadas da parcela.

Os dois experimentos foram instalados em delineamento em blocos casualizados completos com seis repetições. No primeiro experimento, foram avaliadas as progênies 1 a 45 e como testemunhas, a progênie 120 e a cultivar Verdão. No segundo experimento, foram avaliadas as progênies 46 a 85 e as testemunhas. A progênie 120 e a cultivar Verdão foram utilizadas como testemunhas para possibilitar a análise dos dois experimentos.

As estimativas dos parâmetros genéticos e a predição dos valores genéticos das progênies foram obtidas pela metodologia de modelos lineares mistos, utilizando-se o programa R versão 3.1.1 (R Development Core Team, 2011). A análise de representatividade do número mínimo de progênies foi realizada pelo método de simulação de subamostras (Lessman \& Atkins, 1963; Meier \& Lessman, 1971), utilizando-se o aplicativo computacional Genes (Cruz, 2006).

A simulação iniciou-se com subamostras de dez progênies. $\mathrm{O}$ aumento do tamanho das subamostras foi de uma progênie de uma rodada para a outra. $\mathrm{O}$ número de progênies foi sucessivamente aumentado até se atingir o total de 85. Para cada tamanho de subamostra fizeram-se 10 rodadas de forma aleatória com reposição. Em cada subamostra, foi feita uma análise de variância e foram estimados os parâmetros genéticos, obtendo-se em seguida a média das 10 subamostras do mesmo tamanho. Determinaram-se, também, as retas dos limites superiores e inferiores da média mínima não significativa (LMNS), pelo teste t a 5\% de probabilidade, tomando-se como referência a média obtida com as 85 famílias.

\section{RESULTADOS E DISCUSSÃO}

As maiores estimativas de variância genética foram para o número de dias para início do pendoamento e para massa fresca, indicando que nesta população há condições favoráveis para seleção e melhoramento desses caracteres (Tabela
1). Quanto maior a variação genética existente, maiores são as possibilidades de ganhos genéticos com a seleção. Todas as variâncias genéticas foram superiores às variâncias ambientais, exceto para altura de plantas.

$\mathrm{O}$ coeficiente de variação genética possibilita fazer inferências sobre a variabilidade genética entre os diferentes caracteres, auxilia na seleção de genótipos superiores e permite comparar os níveis de variabilidade genética presente em diferentes genótipos, ambientes e caracteres (Ferrão et al., 2008). O coeficiente de variação genética variou de 0,08 a 0,58 para os caracteres altura de plantas e massa fresca (Tabela 1).

Altas estimativas de herdabilidade indicam a possibilidade de selecionar genótipos superiores com maior segurança. A herdabilidade foi considerada alta para todos os caracteres avaliados, exceto para altura de plantas (Tabela 2). Desse modo, há expectativa de ganhos com a seleção de genótipos com pendoamento mais tardio e mais pro-

Tabela 1. Parâmetros genéticos estimados para os caracteres número de dias para início do pendoamento (NDIP), altura de plantas (AP), diâmetro do caule (DC) e massa fresca (MF) de progênies de meio-irmãos de coentro \{genetic parameters estimated for the characters number of days to the beginning of bolting (NDIP), plant height (AP), stem diameter (DC), and fresh weight (MF) of half-sib coriander progenies\}. Recife, UFRPE, 2012.

\begin{tabular}{lcccc}
\hline \multirow{2}{*}{ Parâmetros genéticos } & \multicolumn{4}{c}{ Caracteres } \\
\cline { 2 - 5 } & NDIP & AP & DC & MF \\
\hline $\mathrm{V}_{\mathrm{g}}$ & 29,4774 & 2,4240 & 0,0263 & 13,4976 \\
$\mathrm{~V}_{\mathrm{a}}$ & 3,6126 & 8,2986 & 0,0114 & 5,1342 \\
$\mathrm{~V}_{\mathrm{f}}$ & 33,0900 & 10,7226 & 0,0377 & 18,6318 \\
$\mathrm{~h}^{2}$ & 89,08 & 22,61 & 69,71 & 72,44 \\
Acurácia & 94,38 & 47,55 & 83,49 & 85,11 \\
$\mathrm{CV}_{\mathrm{g}}$ & 0,15 & 0,08 & 0,33 & 0,58 \\
$\mathrm{CV}_{\mathrm{a}}$ & 0,05 & 0,14 & 0,22 & 0,36 \\
$\mathrm{CV}_{\mathrm{g}} / \mathrm{CV}_{\mathrm{a}}$ & 2,86 & 0,54 & 1,52 & 1,62 \\
\hline $\mathrm{V}_{\mathrm{a}}$ & &
\end{tabular}

Variância fenotípica $\left(\mathrm{V}_{\mathrm{f}}\right)$, variância ambiental $\left(\mathrm{V}_{\mathrm{a}}\right)$, variância genética $\left(\mathrm{V}_{\mathrm{g}}\right)$, herdabilidade em nível de média da progênie $\left(\mathrm{h}^{2}\right)$, coeficiente de variação genética $\left(\mathrm{CV}_{\mathrm{g}}^{\mathrm{g}}\right)$, coeficiente de variação ambiental $\left(\mathrm{CV}_{\mathrm{a}}\right)$ e razão entre coeficiente de variação genética e ambiental $\left(\mathrm{CV}_{\mathrm{g}} / \mathrm{CV}_{\mathrm{a}}\right)$ \{ phenotypic variance $\left(\mathrm{V}_{\mathrm{f}}\right)$, environmental variance $\left(\mathrm{V}_{\mathrm{a}}\right)$, genetic variance $\left(\mathrm{V}_{\mathrm{g}}\right)$, heritability at family mean level $\left(\mathrm{h}^{2}\right)$, genetic variation coefficient $\left(\mathrm{CV}_{\mathrm{g}}\right)$, environmental variation coefficient $\left(\mathrm{CV}_{\mathrm{a}}\right)$, and genetic and environmental variation coefficient ratio $\left(\mathrm{CV}_{\mathrm{g}} / \mathrm{CV}_{\mathrm{a}}\right)$ \}.

Tabela 2. Valores estimados do número mínimo de famílias de meio-irmãos adequado para representar uma população de coentro derivada da cultivar Verdão, avaliando-se a média e a variância genética $\left(\mathrm{V}_{\mathrm{g}}\right)$, e os limites mínimos não significativos (LMNS) da característica \{estimated values of the minimum number of suitable half-sib progenies to represent a population of coriander derived from cultivar Verdão, evaluating the mean and the genetic variance $\left(\mathrm{V}_{\mathrm{g}}\right)$, and the minimum non-significant limits (LMNS) of the characteristic $\}$. Recife, UFRPE, 2012.

\begin{tabular}{lcccc}
\hline & \multicolumn{4}{c}{ Número mínimo de progênies } \\
\cline { 2 - 5 } Caracteres & Média (Me) & LMNS da Me & $\begin{array}{c}\text { Variância } \\
\text { genética }\left(\mathbf{V}_{\mathbf{g}}\right)\end{array}$ & LMNS da V $_{\mathbf{g}}$ \\
\hline NDIP & 78 & 13 & 70 & 12 \\
AP & 69 & 17 & 69 & 15 \\
DC & 70 & 12 & 65 & 10 \\
MF & 68 & 11 & 67 & 9 \\
\hline
\end{tabular}

Número de dias para início do pendoamento (NDIP), altura de plantas (AP), diâmetro do caule (DC) e massa fresca (MF) \{number of days to the beginning of bolting (NDIP), plant height (AP), stem diameter (DC) and fresh weight (MF)\}. 
Tabela 3. Valores genéticos das progênies de meio-irmãos de coentro para os caracteres número de dias para início do pendoamento (NDIP), altura de plantas (AP), diâmetro do caule (DC) e massa fresca (MF) \{genetic value of half-sib coriander progenies for the characters number of days to the beginning of bolting (NDIP), plant height (AP), stem diameter (DC), and fresh weight (MF)\}. Recife, UFRPE, 2012.

\begin{tabular}{|c|c|c|c|c|c|c|c|}
\hline Progênie & NDIP & Progênie & $\mathbf{A P}$ & Progênie & DC & Progênie & MF \\
\hline 45 & 43,4209 & 84 & 20,7723 & 45 & 0,7514 & 22 & 10,4699 \\
\hline 84 & 42,9450 & 81 & 20,6027 & 44 & 0,6584 & 44 & 10,1826 \\
\hline 44 & 42,3816 & 22 & 20,5718 & 22 & 0,6329 & 45 & 10,1415 \\
\hline 22 & 41,6392 & 44 & 20,5153 & 36 & 0,5957 & 84 & 9,7014 \\
\hline 83 & 41,4602 & 67 & 20,4520 & 20 & 0,5888 & 74 & 8,2879 \\
\hline 54 & 41,3118 & 51 & 20,3201 & 72 & 0,5724 & 81 & 7,9760 \\
\hline 66 & 40,8664 & 74 & 20,3185 & 71 & 0,5689 & 51 & 7,8846 \\
\hline 85 & 40,5694 & 85 & 20,3013 & 19 & 0,5632 & 79 & 7,8468 \\
\hline 51 & 40,2725 & 16 & 20,2703 & 41 & 0,5574 & 54 & 7,8021 \\
\hline 67 & 39,9755 & 79 & 20,2259 & 10 & 0,5516 & 20 & 7,6784 \\
\hline 41 & 39,4121 & 31 & 20,2138 & 16 & 0,5504 & 72 & 7,6766 \\
\hline 57 & 39,3816 & 35 & 20,2138 & 59 & 0,5399 & 71 & 7,5184 \\
\hline 78 & 39,3816 & 6 & 20,1950 & 35 & 0,5342 & 80 & 7,4967 \\
\hline 53 & 39,2332 & 59 & 20,1694 & 84 & 0,5341 & 85 & 7,4870 \\
\hline 72 & 39,0847 & 87 & 20,1599 & 8 & 0,5318 & 41 & 7,4406 \\
\hline 42 & 38,9667 & 56 & 20,1506 & 1 & 0,5307 & 83 & 7,4085 \\
\hline 81 & 38,9362 & 78 & 20,1506 & 74 & 0,5212 & 16 & 7,3367 \\
\hline 43 & 38,8183 & 42 & 20,1385 & 81 & 0,5120 & 19 & 7,2836 \\
\hline 64 & 38,7878 & 37 & 20,1008 & 32 & 0,5109 & 36 & 7,2438 \\
\hline 37 & 38,6698 & 19 & 20,0820 & 85 & 0,5085 & 32 & 7,2389 \\
\hline 59 & 38,6393 & 45 & 20,0820 & 27 & 0,5074 & 67 & 7,2335 \\
\hline 16 & 38,5213 & 80 & 20,0656 & 37 & 0,5074 & 5 & 7,1737 \\
\hline 20 & 38,5213 & 46 & 20,0570 & 66 & 0,5062 & 10 & 7,1725 \\
\hline 19 & 38,0759 & 5 & 20,0443 & 34 & 0,5051 & 57 & 7,0680 \\
\hline 36 & 37,9274 & 54 & 20,0187 & 53 & 0,5050 & 59 & 7,0318 \\
\hline Média & 37,2165 & - & 19,8937 & - & 0,4899 & - & 6,3398 \\
\hline
\end{tabular}

dutivas. Melo et al. (2009b) obtiveram maior estimativa de herdabilidade para o caráter número de plantas pendoadas, mostrando que em progênies de coentro da cultivar Verdão há variabilidade genética para tolerância ao calor e essa característica pode ser explorada por programas de melhoramento.

A relação $\mathrm{CV}_{\mathrm{g}} / \mathrm{CV}_{\mathrm{e}}$ foi superior à unidade para todos os caracteres estudados, exceto para altura de plantas (Tabela 2). Confirmando que o melhoramento desse caráter é inviável. A relação $\mathrm{CV}_{\mathrm{g}} / \mathrm{CV}_{\mathrm{e}}$ e a herdabilidade são parâmetros que indicam o sucesso na seleção de genótipos superiores (Faluba et al., 2010).

A acurácia seletiva indica a confian- parâmetros genéticos para esse caráter (Tabela 2).

$\mathrm{Na}$ tabela 3, foi feito o ranqueamento das 25 progênies de meio-irmãos com o maior valor genético para cada caráter estudado. Observou-se que 13 dessas progênies apresentaram valores genéticos superiores para os caracteres número de dias para início do pendoamento, diâmetro do caule e massa fresca. Dessa forma, as progênies $16,19,20,22,36$, $41,44,45,59,72,81,84$ e 85 podem ser selecionadas para dar continuidade ao programa de melhoramento de coentro. Mostrando que é possível encontrar progênies com alelos favoráveis para os três caracteres.

Souza et al. (2008), estudando a variabilidade genética de progênies de alface tolerantes ao calor observaram que maiores médias de diâmetro do caule e massa fresca podem ser obtidos quando a emissão do pendão floral é reduzida. Segundo Melo et al. (2009b), após a planta de coentro iniciar o pendoamento, suas reservas são deslocadas para a formação do pendão floral, havendo uma redução no tamanho e qualidade das folhas. Por isso deve ser feita a seleção de plantas que produzam mais folhas em menos tempo e com o pendoamento mais tardio.

A estimativa de parâmetros genéticos permitiu concluir que as progênies de coentro apresentam variabilidade genética para os caracteres número de dias para início do pendoamento, diâmetro do caule e massa fresca, indicando que estas características podem ser exploradas em futuros programas de melhoramento. O número mínimo adequado para estimar os parâmetros genéticos e representar a população de coentro é de 68 progênies.

As progênies 16, 19, 20, 22, 36, 41, $44,45,59,72,81,84$ e 85 possuem alelos favoráveis para as características avaliadas podendo ser selecionadas para dar continuidade ao programa de melhoramento de coentro para tolerância ao calor.

\section{AGRADECIMENTOS}

Agradecemos à UFRPE pelo apoio 
institucional; à CAPES e ao CNPq pela concessão de bolsa de mestrado, à FACEPE pelo financiamento do projeto e à HORTIVALE pela disponibilização de sementes de coentro.

\section{REFERÊNCIAS}

ABCSEM. Associação Brasileira do Comércio de Sementes e Mudas. 2010, 16 de março de 2013. Pesquisa_mercado_2009. Disponível em: http://www.abcsem.com.br/docs/.

CRUZ CD. 2006. Programa Genes v.7.0: biometria. Viçosa: UFV. 382p.

CRUZ CD; CARNEIRO PSC. 2006. Modelos biométricos aplicados ao melhoramento genético. Viçosa: UFV. 585p.

FALUBAJS; MIRANDA GV; LIMA RO; SOUZA LV; DEBEM EA; OLIVEIRA AMC. 2010. Potencial genético da população de milho UFV 7 para o melhoramento em Minas Gerais. Ciência Rural 40: 1250-1256.

FERRÃO RG; CRUZ CD; FERREIRA A.; CECON PR; FERRÃO MAG; FONSECA AFA; CARNEIRO PCS; SILVA MF. 2008. Parâmetros genéticos em café Conilon. Pesquisa Agropecuária Brasileira 43: 61-69.
GRANATE MJ; CRUZ CD; PACHECO CAP. 2001. Número mínimo de famílias de meiosirmãos para representar uma população de milho-pipoca. Revista Ceres 48: 209-221.

HORTIVALE. 2011, 16 de março de 2013. Disponível em: http://www.hortivale.com.br.

KUMAR A; SINGH R; CHHILLAR RK. 2008. Influence of omitting irrigation and nitrogen levels on growth, yield and water use efficiency of coriander (Coriandrum sativum). Acta Agronomica Hungarica 56: 69-74.

LESSMAN KJ; ATKINS RE. 1963. Optimum plot size and relative efficiency of lattice design for grain sorghum yield tests. Crop Science 3: 477-481.

MACIEL GM; COSTA CP; SALA FC. 2012. Linhagens de coentro com pendoamento tardio sob dois sistemas de plantio. Horticultura Brasileira 30: 607-612.

MEIER VD; LESSMAN KJ. 1971. Estimation of optimum field plot shape and size for testing yield in Crambe abyssinica. Crop Science 1: 648-650.

MELO RA; MENEZES D; RESENDE LV; WANDERLEY JÚNIOR LJG; MELO PCT; SANTOS VF. 2009a. Caracterização morfológica de genótipos de coentro. Horticultura Brasileira 27: 371-376.

MELO RA; MENEZES D; RESENDE LV; WANDERLEY JÚNIOR LJG; SANTOS VF;
MESQUITA JCP; MAGALHÃES AG. 2009b. Variabilidade genética em progênies de meiosirmãos de coentro. Horticultura Brasileira 27: 325-329.

OKUT N; YIDIRIM B. 2005. Effects of different row spacing and nitrogen doses on certain agronomic characteristics of coriander (Coriandrum sativum). Pakistan Journal of Biological Sciences 8: 901-904.

OLIVEIRA AP; MELO PCT; WANDERLEY JÚNIOR LJG; ALVES AU; MOURA MF; OLIVEIRA ANP. 2007. Desempenho de genótipos de coentro em Areia. Horticultura Brasileira 25: 252-255.

PIMENTEL AJB; GUIMARÃES JFR; SOUZA MA; RESENDE MDV; MOURALM; ROCHA JRASC; RIBEIRO G. 2014. Estimação de parâmetros genéticos e predição de valor genético aditivo de trigo utilizando modelos mistos. Pesquisa Agropecuária Brasileira 49: 882-890.

R Development Core Team. 2011. R: A language and environment for statistical computing. $\mathrm{R}$ Foundation for Statistical Computing, Vienna, Austria. Disponível em: http://www.R-project. org/.

SOUZA MCM; RESENDE LV; MENEZES D; LOGES V; SOUTE TA; SANTOS VF. 2008. Variabilidade genética para características agronômicas em progênies de alface tolerantes ao calor. Horticultura Brasileira 26: 354-358. 